\title{
Legal Structure, Rights and Enforceability
}

\author{
PA UL CRAIG
}

\subsection{Introduction}

Brexit was a complex political process and this was no less so legally. It entailed five principal legal instruments. There were two treaties: the Withdrawal Agreement (WA), which settled the terms on which the UK left the $\mathrm{EU}^{1}$ and the Trade and Cooperation Agreement (TCA), which contained the detailed provisions as to the relationship between the UK and the EU on trade and other issues. ${ }^{2}$ The three principal UK statutes are the European Union (Withdrawal) Act 2018 (EUWA 2018), which dealt with the acquis of EU law within the UK post-withdrawal; the European Union (Withdrawal Agreement) Act 2020 (EUWAA 2020), which gave legal force in UK law to the WA, in part by amending EUWA 2018; and the European Union (Future Relationship) Act 2020 (EUFRA), which incorporated the TCA into UK law. The focus of this chapter is on private rights that flow from the preceding instruments. This is a complex topic, not all dimensions of which can be addressed within the available space. The discussion will therefore concentrate on four such issues, which are central to the post-Brexit schema and to the situation in Northern Ireland.

\subsection{The TCA, EUFRA and Rights}

The TCA contains a plethora of enforcement provisions. ${ }^{3}$ The present focus is as to whether it has direct effect, or anything analogous thereto.

${ }^{1}$ Agreement on the withdrawal of the United Kingdom of Great Britain and Northern Ireland from the European Union and the European Atomic Energy Community, OJ 2019 No. C384 I/01.

2 The Trade and Cooperation Agreement between the European Union and the European Atomic Energy Community, of the One Part, and the United Kingdom of Great Britain and Northern Ireland, of the Other Part, OJ 2021 No. L149/10.

3 P Craig, 'Brexit, a Drama, the Endgame - Part II: Trade, Sovereignty and Control' (2021) 46 European Law Review 129. 
The answer would appear to be negative, given the wording of Article 5, which provides:

Without prejudice to Article SSC.67 of the Protocol on Social Security Coordination and with the exception, with regard to the Union, of Part Three of this Agreement, nothing in this Agreement or any supplementing agreement shall be construed as conferring rights or imposing obligations on persons other than those created between the Parties under public international law, nor as permitting this Agreement or any supplementing agreement to be directly invoked in the domestic legal systems of the Parties.

The TCA would seem therefore to be unequivocally clear: it does not create direct effect and it takes effect solely as an international law obligation between the contracting parties. This prima facie conclusion must, however, be seen in the light of section 29 EUFRA, which states:

Existing domestic law has effect on and after the relevant day with such modifications as are required for the purposes of implementing in that law the Trade and Cooperation Agreement or the Security of Classified Information Agreement so far as the agreement concerned is not otherwise so implemented and so far as such implementation is necessary for the purposes of complying with the international obligations of the United Kingdom under the agreement.

The rationale for section 29 is temporal exigency. The normal procedure for addressing inconsistencies between a treaty and existing UK law is through statutory instruments, facilitated by so-called Henry VIII clauses. ${ }^{4}$ Section 31 EUFRA contains the now routine Henry VIII clause. However, the TCA was agreed at the eleventh hour, and there was therefore no time to make the requisite statutory instruments. Section 29 was the legislative response to this problem.

It is important to note that it is not merely an interpretive obligation. It is expressive of substantive change: existing law 'has effect' on and after exit day with such 'modifications' as necessary to implement the TCA, assuming that the inconsistency has not otherwise been addressed. The phrase 'existing law' can clearly cover the common law as well as statute. Common law provisions that are inconsistent with the TCA will, therefore, fall within section 29 .

The salient issue for present purposes is whether section 29 EUFRA renders the TCA directly effective in national courts, notwithstanding

${ }^{4}$ Such clauses enable primary legislation to be amended or repealed through statutory instruments. 
Article 5 TCA. There are two conceptual issues to be borne in mind in this respect.

The first is the duality of meaning as to direct effect. It is sometimes used to connote individual rights, also known as subjective direct effect, in the sense of subjective rights, as that phrase would be understood in civil law systems. It is also used in a looser sense, sometimes known as objective direct effect, connoting the idea that a provision of EU law that is sufficiently certain and precise can be legally invoked by an individual. ${ }^{5}$ The second is the duality attendant on statutes and rights as a matter of UK domestic law. A statute may create enforceable rights for individuals, but it will not always do so. It may grant powers or impose duties on a public body or private party, which may not be enforceable by an individual. This is attested to by, for example, the law relating to standing ${ }^{6}$ and breach of statutory duty. ${ }^{7}$ It might therefore be argued that section 29 would not in all instances necessarily generate actionable rights that flow from the TCA. This may be so, but it is nonetheless difficult to deny that it could do so. The salient issue is whether the particular pre-existing statute is amenable to enforcement, or reliance on, by a private party. Consider the following examples.

Scenario 1 is an instance of collateral attack. A customs authority sues a trader for non-compliance with existing UK customs law. The trader responds by claiming rightly that the customs law is inconsistent with TCA provisions, and that therefore the national law must now, in the light of section 29, bear a meaning that is consistent with the TCA. If the trader can successfully make this argument, then it is able to rely on TCA provisions in national law. The conceptual foundation for this is UK law, in the form of section 29, which carries the force of parliamentary sovereignty. However, the consequence is that TCA provisions thereby become enforceable in national courts.

Scenario 2 takes the form of direct attack. A trader instigates an action concerning public procurement. It argues that existing UK law embodies procedures that are inconsistent with the TCA provisions on procurement, and that therefore, in accord with section 29, the existing law must have effect with the requisite modifications. It can be assumed for the sake of

${ }^{5}$ P Craig and G de de Búrca, EU Law, Text, Cases and Materials (Oxford University Press 2020) ch 8.

${ }^{6}$ P Craig, Administrative Law (9th edn, Sweet \& Maxwell 2021) ch 25.

7 Marksenis and Deakin's Tort Law (Simon Deakin and Zoe Adams eds, 8th edn, Oxford University Press 2019) ch 7. 
argument that procedures such as those in the TCA would be regarded as giving rise to individual rights if they were embodied in a UK statute. If the trader can do this, then it is able to rely on TCA provisions in national law.

We will have to await the view of the Supreme Court on the preceding issues. The following considerations are relevant in this regard. It might appear counter-intuitive for the TCA to be legally enforceable in UK courts, given the wording of Article 5. However, it would be highly problematic for the defendant/claimant in the previous scenarios not to be able to rely on the TCA provision. There would, for example, be profound legal problems with enabling a customs authority to sue a trader on the basis of a law that no longer contains the legal provisions that constitute the offence, since they have been 'modified' and 'have effect' subject to the TCA through section 29 EUFRA.

It should also be borne in mind that Article 5 TCA is not denuded of all effect, even if some form of direct effect operates through section 29 EUFRA. This is because it operates only in relation to existing law, and therefore the denial of direct effect in the TCA would continue to operate in relation to post-EUFRA legislation. Thus, a trader could not rely on the TCA to complain that legislation enacted in 2021 was inconsistent with the TCA. The other limit is that section 29 operates only where there is existing law that is inconsistent with the TCA. It does not cover the situation where there is no national law on the matter.

The final consideration is that insofar as Article 5 TCA is compromised, it is through the will of Parliament as expressed in section 29 EUFRA. This is important, given that this Article is framed in terms 'nothing in the TCA shall be construed' as giving rise to enforceable rights. This does not preclude Parliament from choosing to do so, or enacting legislation that has this effect, more especially given that section 29, thus construed, would avail UK and EU traders alike, assuming that the existing UK law was inconsistent with TCA provisions.

\subsection{The TCA, the Level Playing Field and Rights}

The TCA level playing field provisions cover a variety of areas: competition, subsidies, state-owned enterprises, taxation, labour and social standards, environment and climate, other instruments for trade and sustainable development, and horizontal provisions. The Political Declaration attached to the WA attested to the centrality the EU accorded 
to the level playing field restrictions. ${ }^{8}$ Prime Minister Theresa May was willing to accept such regulatory alignment, since it would facilitate the frictionless trade that she sought. ${ }^{9}$ When Boris Johnson became Prime Minister, he made clear that his stance towards the trade negotiations was markedly different. This became readily apparent from his Greenwich speech, ${ }^{10}$ and from the UK's Negotiation Document. ${ }^{11}$ The latter document affirmed that the UK would no longer be part of the EU Customs Union or Single Market. ${ }^{12}$ It stated, moreover, that the envisaged agreement would be between sovereign equals and that the government would not 'negotiate any arrangement in which the UK does not have control of its own laws and political life'. The UK would not therefore 'agree to any obligations for our laws to be aligned with the EU's, or for the EU institutions, including the Court of Justice, to have any jurisdiction in the UK'. ${ }^{13}$

The TCA reflects the hard-fought battles over the parties' degree of freedom and constraint on these issues. It is evident in the very preamble to the TCA, and the same duality runs through the substantive text. The provisions are complex and are examined in detail in later chapters. ${ }^{14}$ The present discussion focuses on two general issues that pertain to private rights and the level playing field provisions.

\subsubsection{Private Rights and the Level Playing Field: Conceptual Relationship}

The first issue is the conceptual relationship between the level playing field provisions that generate rights of action in national courts and Article 5 TCA. The latter, as noted in Section 3.2, provides that, subject to limited exceptions, the TCA does not generate rights. The level playing

${ }^{8}$ Political declaration setting out the framework for the future relationship between the European Union and the United Kingdom, OJ 2019 No. C384 I/02.

9 The Future Relationship between the United Kingdom and the European Union, Cm 9593 (2018); P Craig, 'Brexit, a Drama, the Endgame - Part I' (2020) 45 European Law Review 163 at 171-72; K Armstrong, 'Regulatory Autonomy after EU Membership: Alignment, Divergence and the Discipline of Law' (2020) 45 European Law Review 207.

10 Prime Minister Boris Johnson, Greenwich Speech, 3 February 2020, www.gov.uk/govern ment/speeches/pm-speech-in-greenwich-3-february-2020.

11 The Future Relationship with the EU, The UK's Approach to Negotiations, CP211, February 2020.

12 The Future Relationship with the EU, Introduction [2].

13 The Future Relationship with the EU, Introduction [5].

${ }^{14}$ See especially Chapters $18-22$ and 25. 
field provisions are not one of the two exceptions to Article 5. This then begs the question as to the relationship between the level playing field provisions stipulating rights of action in national courts, and the denial of direct effect for the TCA.

The answer is as follows. If the UK, as a contracting party to the TCA, failed to provide for the rights specified in the TCA level playing field provisions concerning causes of action in national courts, and judicial review, an individual could not argue in a UK court that the obligation to provide for such measures generated rights that were enforceable in national courts. Such an argument would be precluded by Article 5 TCA. The failure to fulfil such obligations would generate other TCA remedial mechanisms, but it could not be redressed through an action brought by an individual in a UK national court, since the relevant TCA provisions are not directly effective.

\subsubsection{Private Rights and the Level Playing Field: UK Implementation}

The second issue is related, but distinct. It concerns the scope of the rights granted by the level playing field provisions and whether they can be effectuated by existing UK law. The provisions concerning subsidies can be taken by way of example.

The TCA contains remedial obligations to effectuate the substantive duties in relation to subsidies. ${ }^{15}$ Each party must establish an independent body that must have an 'appropriate role in its subsidy control regime,, ${ }^{16}$ which in the UK will be the Competition and Markets Authority. There must be access to courts/tribunals to review subsidy decisions to ensure compliance with the relevant TCA principles and conditions, and to hear interested parties that have standing under that party's law. The parties must ensure that courts/tribunals have power to impose remedies, including suspension, prohibition or requirement of action by the granting authority, the award of damages, and recovery of subsidy from its beneficiary, if and to the extent that they are available under the respective laws on the date of entry into force of the TCA. ${ }^{17}$ Private enforcement takes the form of an action brought by an interested party before the relevant UK court. ${ }^{18}$ The

15 The situation in Northern Ireland is different, although Art 10 of the Protocol could have ramifications for the UK.

16 Art 371 TCA.

17 Art 372(1) TCA, subject to qualifications in Art 372(3).

18 'Interested party' means any natural or legal person, economic actor or association of economic actors whose interest might be affected by the granting of a subsidy, in 
TCA specifies that each party shall have in place an effective mechanism of recovery in respect of subsidies, without prejudice to other remedies that exist in that party's law. The court must be able to order recovery where, for example, the subsidy has been granted in breach of the principles contained in the TCA, or where the grantor of the subsidy acted outside its powers. ${ }^{19}$

The remedial obligations are, however, qualified, although the nature of the qualification is itself contestable. Articles 372(3)-(4) TCA state:

(3) Without prejudice to the obligations to maintain or, where necessary, to create the competencies, remedies and rights of intervention referred to in paragraphs 1 and 2 of this Article, and Article 373, nothing in this Article requires either Party to create rights of action, remedies, procedures, or the scope or grounds of review of decisions of their respective public authorities, beyond those existing under its law on the date of entry into force of this Agreement.

(4) Nothing in this Article requires either Party to widen the scope or grounds of review by its courts and tribunals of Acts of the United Kingdom Parliament, of acts of the European Parliament and the Council of the European Union, or of acts of the Council of the European Union beyond those existing under its law on the date of entry into force of this Agreement. ${ }^{20}$

There is clearly a tension in Article 372(3). Indeed, it might even be that the two halves were drafted by different contracting parties and then bolted together. The provision is best read as stating that the contracting parties have a Treaty obligation to maintain or create the relevant remedies and rights of intervention thus specified, but not if this requires the creation of rights or action etc, or grounds of review, of a kind that go beyond those in existing law. The salient point for present purposes is that UK law does contain principles of judicial review that allow a court to suspend, prohibit or require action to be taken by the granting authority. ${ }^{21}$ These principles can, without conceptual difficulty, be applied to cover non-compliance with the conditions for the award of subsidies contained in the TCA. UK law also has tortious causes of action for the award of damages, provided that the requisite criteria for the particular action are met. ${ }^{22}$

particular the beneficiary, economic actors competing with the beneficiary or relevant trade associations of the respective parties, Art 369(6) TCA.

19 Art 373(2) TCA.

${ }^{20}$ Art 372(3)-(4) TCA.

${ }^{21}$ Craig (n 6) chs 26-27.

${ }^{22}$ Craig (n 6) ch 30. 
There is a further limitation, which precludes recovery of a subsidy when it is granted 'on the basis of an Act of Parliament, ${ }^{23}$ and UK governments might be tempted to give these words a broad interpretation, to prevent recovery where a minister grants aid pursuant to statutory discretionary power. This does not, however, render the subsidy lawful, and the other remedial duties continue to apply. Thus, an action could still be brought to prevent the subsidy being given, or to claim damages if it was awarded contrary to the TCA criteria. This possibility is in turn subject to Article 372(4) TCA, set out above, which would preclude an action if the subsidy was directly mandated by a statute. If such an award were in breach of the TCA subsidy provisions it could nonetheless lead to the triggering of other remedial mechanisms, in particular those relating to public enforcement between the contracting parties.

\subsection{The EUWA 2018, Retained Law and Rights}

The EUWA 2018 served primarily to convert the EU legal acquis into UK law. The rationale for the legislation is readily apparent. ${ }^{24}$ The UK had been a member of the EU since 1972, and many areas of life were regulated by EU law. Directives were already transformed into UK law. There was, however, much EU law, such as regulations, that was directly applicable, taking effect in domestic law when enacted by the EU, without the need for further national legislation. The regulatory architecture in any area was typically an admixture of Treaty provisions, directives, regulations and decisions. It would, in theory, have been possible to reject this regulatory material in the event of Brexit. This would, however, have led to chaos. The EU rules regulated matters from product safety to creditworthiness of banks, from securities markets to intellectual property and from the environment to consumer protection. There could not simply be a legal void in these areas, and pre-existing UK law would often not exist.

This was the rationale for the EUWA 2018, the foundational premise being that the entirety of the EU legal acquis was converted into UK law. Parliament could then decide, in two stages, which measures to retain, amend or repeal. Stage one was to ensure that the EU rules retained as

23 Art 373(5) TCA.

24 Legislating for the United Kingdom's Withdrawal from the European Union, Cm 9446 (2017), [1.13]. 
domestic law were fit for legal purpose when the UK left the EU; stage two was the period post-Brexit, when Parliament could decide at greater leisure whether it wished to retain these rules.

An important issue concerns the EUWA 2018, section 3 of which deals with the incorporation of direct EU legislation, such as regulations. It provides that, so far as operative immediately before exit day, it forms part of domestic law on and after exit day. The apposite issue for the present chapter is whether this comes with direct effect in a post-Brexit world, such that individuals can derive rights from regulations when they would have had these prior to Brexit, with the consequence that they can rely on such rights without the need to prove the conditions for breach of statutory duty. There are three arguments in favour of direct effect.

The first is that it coheres with the purpose of EUWA 2018, which was to bring the entire acquis into UK law and then decide what to do thereafter. The second argument is that it is consistent with section 4 EUWA 2018, which brings directly effective rights into UK law, thereby precluding any argument that this is contrary to the intent of the EUWA. The third reason that warrants this conclusion is that it is consistent with section 4(2)(a) EUWA 2018, which provides that section 4(1) does not apply to any rights etc so far as they form part of domestic law by virtue of section 3. This thereby expressly contemplates that rights can flow from regulations that are incorporated via section 3 .

\subsection{The WA, the Protocol and Rights}

The final section of this chapter addresses rights-based issues that pertain specifically to Northern Ireland. The starting point is Article 4(1) of the WA, which states:

The provisions of this Agreement and the provisions of Union law made applicable by this Agreement shall produce in respect of and in the United Kingdom the same legal effects as those which they produce within the Union and its Member States. Accordingly, legal or natural persons shall in particular be able to rely directly on the provisions contained or referred to in this Agreement which meet the conditions for direct effect under Union law.

Article 4(1) thus gives direct effect to the provisions of the WA and the provisions of EU law made applicable by the Agreement, when they meet the requisite conditions for direct effect. This binding treaty obligation was then duly incorporated into UK law, in accord with dualist precepts, 
through amendment to the EUWA 2018. Section 7A EUWA made provision for directly effective rights flowing from Article 4(1) to be enforceable in national courts. This was complemented by section $8 \mathrm{C}$ EUWA, which concerns Northern Ireland. It empowers a minister of the Crown to make regulations as the minister considers appropriate to, inter alia, implement the Protocol and supplement the effect of section 7A EUWA in relation to the Protocol. There are multiple opportunities for individuals to bring actions based on rights that flow from the Protocol. Two examples will suffice for present purposes.

An individual might claim that action taken by state authorities is contrary to one of the many Single Market regulations that continue to apply in Northern Ireland post-Brexit. Annex 2 of the Protocol renders a very great many Single Market provisions applicable to Northern Ireland, and many of these regulations, decisions and directives fulfil the conditions for direct effect as developed by the CJEU. Thus, provided that the particular article of the regulation, directive or decision is sufficiently precise, certain and unconditional, it will generate rights that can be enforced in national courts. There will also be horizontal direct effect for provisions of EU regulations and decisions that continue to apply in Northern Ireland, provided that they meet the preceding criteria. They can therefore be enforced against private parties, as well as emanations of the state. The courts in Northern Ireland will adjudicate on such claims, and insofar as any such case relates to Articles 5, 7-10 of the Protocol, there might then be a reference to the CJEU pursuant to Article 12(4) of the Protocol.

Consider a second example, which concerns the powers of EU institutions within the UK. EU institutions are accorded powers pursuant to Article 12(4) of the Protocol. It provides:

As regards the second subparagraph of paragraph 2 of this Article, Article 5 and Articles 7 to 10, the institutions, bodies, offices, and agencies of the Union shall in relation to the United Kingdom and natural and legal persons residing or established in the territory of the United Kingdom have the powers conferred upon them by Union law. In particular, the Court of Justice of the European Union shall have the jurisdiction provided for in the Treaties in this respect. The second and third paragraphs of Article 267 TFEU shall apply to and in the United Kingdom in this respect.

This is further reinforced by Article 12(5), which stipulates that the actions of such Union bodies have the same legal effect as those they produce when such bodies act within the EU. It follows that an individual could argue that 
action by Northern Ireland authorities was invalid because it was inconsistent with imperatives flowing from such EU institutions.

\subsection{Conclusion}

This chapter has addressed some of the difficult issues concerning rights and enforceability that flow from the WA, the TCA and the principal UK legislation dealing with Brexit. Exigencies of space mean that not all such matters have been considered. There will doubtless be litigation that addresses these issues, and resolves some of the uncertainties raised in the preceding discussion. 